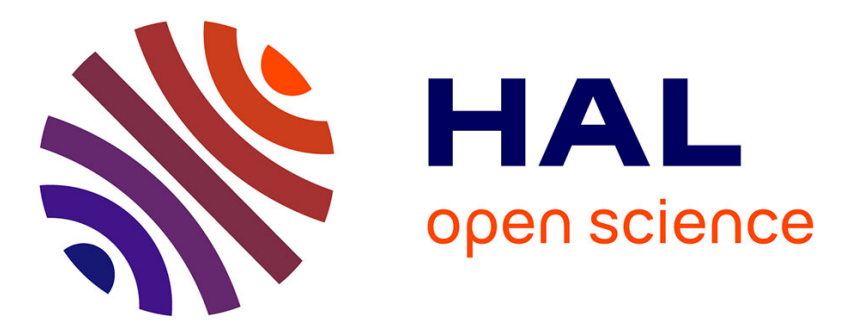

\title{
Lack of anticipatory gaze-orienting responses in patients with right brain damage
}

\author{
Isabelle Viaud-Delmon, Y P Ivanenko, ; E Viaud-Delmon, ; N Mayer, J M \\ Valenza,; A Annoni, J P Rohr,; A Guyot, T Berthoz
}

\section{- To cite this version:}

Isabelle Viaud-Delmon, Y P Ivanenko,; E Viaud-Delmon,; N Mayer, J M Valenza, et al.. Lack of anticipatory gaze-orienting responses in patients with right brain damage. Neurology, 2000, 54, pp.1656-1661. hal-03411694

\section{HAL Id: hal-03411694 \\ https://hal.science/hal-03411694}

Submitted on 2 Nov 2021

HAL is a multi-disciplinary open access archive for the deposit and dissemination of scientific research documents, whether they are published or not. The documents may come from teaching and research institutions in France or abroad, or from public or private research centers.
L'archive ouverte pluridisciplinaire HAL, est destinée au dépôt et à la diffusion de documents scientifiques de niveau recherche, publiés ou non, émanant des établissements d'enseignement et de recherche français ou étrangers, des laboratoires publics ou privés. 


\title{
Lack of anticipatory gaze-orienting responses in patients with right brain damage
}

\author{
Y.P. Ivanenko, PhD; I. Viaud-Delmon, PhD; E. Mayer, PhD; N. Valenza, BA; J.M. Annoni, MD; A. Rohr, BS;
} J.P. Guyot, MD; A. Berthoz, PhD; and T. Landis, MD, PhD

\begin{abstract}
Article abstract-Objective: To study eye movements during cervical proprioceptive stimulation by passive body rotation in darkness, with the head held stationary, in patients with right brain damage and hemineglect. Background: At very low frequency, this stimulation is reported to produce an illusion of head turning in space and eye deviations directed opposite to trunk rotation (in the direction of the illusory head rotation). Methods: Ten normal subjects and seven patients with unilateral cerebral lesions (five right brain-damaged patients with mild to moderate visuospatial neglect, two left brain-damaged patients without neglect) were included in the study. Subjects were seated on a rotating chair. Stimuli consisted of slow sinusoidal passive trunk rotations $\left( \pm 30^{\circ}, 0.01 \mathrm{~Hz}\right)$ while the head was fixed in space. Results: Eye movements directed opposite to trunk rotation were typical for normal subjects and for left brain-damaged patients. In contrast, all right brain-damaged patients showed either eye movements in the direction of trunk rotation or no eye deviations at all. Conclusion: This result could characterize a lack of anticipatory coordinating gaze behavior in patients with right brain damage. Key words: Spatial neglect—Cervico-ocular response_Eye-head coordination-AnticipationHuman.
\end{abstract}

NEUROLOGY 2000;54:1656-1661

Patients with unilateral spatial neglect, which occurs predominantly after right hemisphere damage, are frequently not able to explore the contralesional part of their extrapersonal space. ${ }^{1-4}$ Exploratory eye movements in patients with neglect have been studied thoroughly in static conditions (with stationary head and trunk) but it should be noted that vestibular, optokinetic, and neck proprioceptive stimulation may modify some aspects of the neglect syndrome..$^{5-8}$ Therefore, the study of multisensory integration in these patients might reveal mechanisms underlying space-related behavioral changes that are produced by unilateral cerebral lesions.

It has been hypothesized that the essential factor leading to neglect in brain-damaged patients is an ipsilesional deviation of a body-centered coordinate system. ${ }^{8}$ However, besides the ipsilesional deviation of a subjective midsagittal plane, unilateral cerebral lesions also seem to disturb some integrative hemispheric functions related to the gaze control system. The dominance of the right hemisphere for attentional/intentional mechanisms directed at external space ${ }^{1}$ might involve as well the coordinating behavior of eye and body movement in space. For example, single cell recordings in the posterior parietal cortex of primates showed that neuronal activity in this area can be modulated by eye, head, or shoulder rotation. ${ }^{9}$ It is also known from stimulation of the cerebral cortex of epileptic patients that a local cortical discharge can result in conjugate deviation of both the eyes and head..$^{10}$ In patients with neglect, however, few and conflicting data are available concerning the sensory processing involved in coordinating the eyes, head, and trunk. ${ }^{11,12}$ Here we studied oculomotor behavior in patients with unilateral cerebral lesions during cervical stimulation in darkness. We focused our analysis on the compound ocular response (eye deviations), which is a result of the summation of both fast and slow phases of eye movements and can define an orientation strategy. ${ }^{13-16}$ It is known that very slow trunk rotations with the head held earth-fixed evoke in normal subjects a strong illusion of head turning in space and anticipatory eye deviations in the direction of the illusory head rotation. $^{13,17}$ To elicit such illusions, angular velocities and accelerations must be below threshold for the vestibular system (see reference 18). For very slow trunk rotations, the brain cannot distinguish which body segment (head or trunk) is immobile. Therefore, the system of internal representation tends to consider the trunk linked to the support to be stationary in space. We took advantage of this phenomenon to

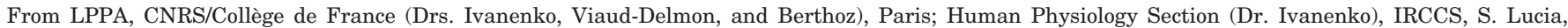

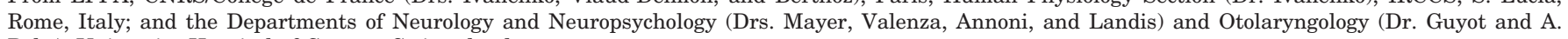
Rohr), University Hospital of Geneva, Switzerland.

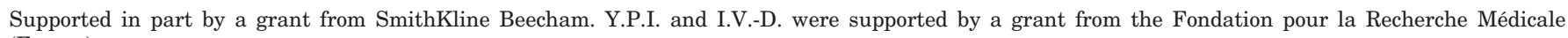
(France).

Received October 21, 1999. Accepted in final form January 18, 2000.

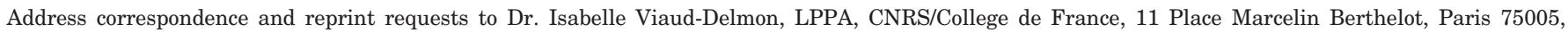
France; e-mail: i.viaud-delmon@college-de-france.fr 


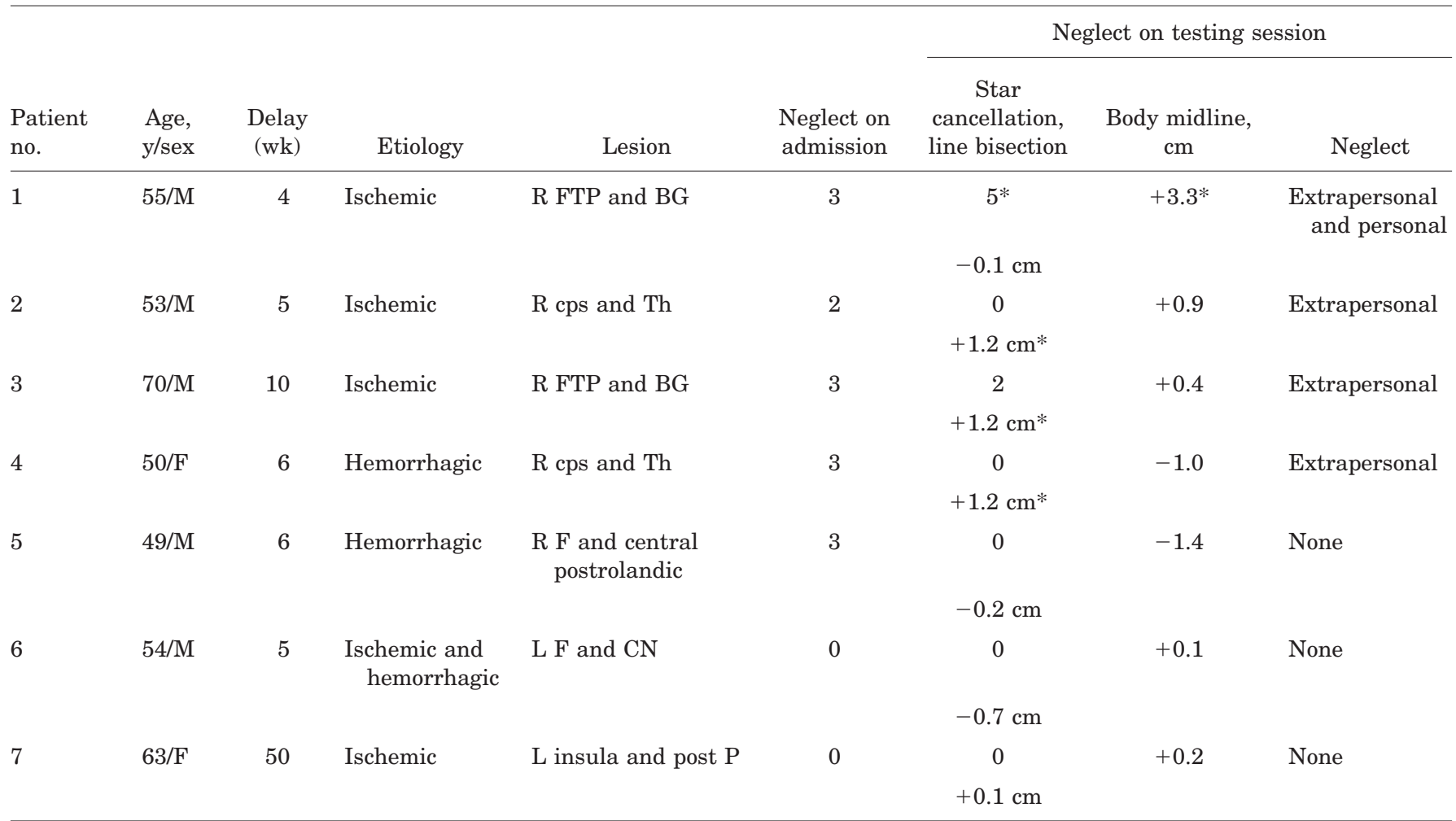

Delay refers to the delay in weeks between the stroke and the experimental session. Locus of cerebral lesion is indicated as follows: $\mathrm{P}=$ parietal; $\mathrm{T}=$ temporal; $\mathrm{F}=$ frontal; $\mathrm{CN}=$ caudate nucleus; $\mathrm{BG}=$ basal ganglia; $\mathrm{Th}=$ thalamus; cps $=$ capsular. Neglect on admission was diagnosed on the basis of a standardized battery of examinations, which included drawing, copying tasks, and a line bisection task. Scoring: $0=$ absent; $1=$ mild; 2 = moderate; $3=$ severe. On experimental session, extrapersonal and personal neglect were assessed. Extrapersonal neglect was quantified by the number of omitted items (significant if $>2$ ) on the side contralateral to the lesion (first line) and by deviation (significant if $>1 \mathrm{~cm}$ ) from the true center of $20.6 \mathrm{~cm}$ lines (second line). Personal neglect was quantified by the deviation from the real midline of the body (+ deviation to the right; - deviation to the left, significant if $>1 \mathrm{~cm}$ ).

* Results considered significant.

investigate the perceptual responses and accompanying eye movements in patients during pure neck somatosensory stimulation, in the absence of visual and vestibular input.

Methods. Patients. Seven right-handed patients with unilateral cerebrovascular lesions were studied: four right brain-damaged (RBD) patients with moderate neglect, one RBD patient without neglect at the time of testing, and two left brain-damaged (LBD) patients without neglect. All were engaged in a motor and/or neuropsychological program at the University Hospital of Geneva. All the patients, even aphasics, could understand the instructions and gave written consent.

Table 1 summarizes data relative to the patients: age, length of illness, locus of the lesion assessed on the basis of CT examination, and neuropsychological evaluation. Extrapersonal neglect was assessed by a star cancellation ${ }^{19}$ and a line bisection task (five trials). ${ }^{20}$ Personal neglect was assessed by an internally developed body-midline judgment task. In this task, the subject was asked to determine when a stylus displaced horizontally from one shoulder to the other reached the middle of his or her back. Ten trials were given to each patient, starting either from the right or the left shoulder. Neglect examination revealed interindividual differences between the RBD pa- tients (see table 1): one of them did not show any sign of either personal neglect or of extrapersonal neglect. In contrast, another patient presented symptoms of neglect in both personal and extrapersonal spaces. The three remaining patients demonstrated extrapersonal neglect in one or both of the tasks, without manifestation of personal neglect. The two LBD patients did not show any manifestation of neglect in both types of tasks (see table 1). At the time of the experiment, all patients had at least some sensory-motor deficit except Patient 6, who had a mild hemiparesis without sensory deficit. Patients 1 and 3 had left hemianopia; the other patients had an intact visual field.

Ten normal right-handed healthy subjects (mean age $42 \pm 15$ years, 4 female and 6 male) were tested and compared with the group of patients. They had no history of neurologic or vestibular disorders. Informed written consent was obtained from all patients and normal subjects.

Experimental setup. Experimental procedure consisted of trunk rotation with head stationary with respect to earth. The subjects were seated on a rotating chair in an upright position blindfolded with eyes open. The head was aligned with the axis of rotation. The subject wore a light helmet and the head was maintained gently fixed in space manually by the experimenter. The head fixation prevented vestibular end-organ stimulation. Thus, a pure neck stimula- 
tion occurred during these trunk-on-head rotations. Stimuli were sinusoidal chair rotations $\left( \pm 30^{\circ}, 0.01 \mathrm{~Hz}\right)$ about the primary position. Peak velocity corresponded to $2 \%$ second. Chair rotations were achieved by a servo-controlled motor. The accuracy of head fixation in space was estimated in two normal subjects by projecting a small light source attached to the subject's head onto a wall (distance $1.5 \mathrm{~m}$ ). Visual inspection by an experimenter revealed that, during neck stimulation, head movements in space did not exceed $\pm 1^{\circ}$. Thus, the contribution of the vestibulo-ocular reflex to eye movements due to imperfect head-in-space stability seemed to be insignificant. It is also worth stressing that eye movements in the direction of illusory head rotation are typical for normal subjects for very slow trunk-on-head rotations and were reported in other studies with different kinds of head fixation (manually, using a helmet; see references 13 and 17). The recording of each trial lasted 200 seconds. This period covered two full cycles of sinusoidal movement. Subjects were instructed to relax and not to resist the imposed rotations. No instructions were given about gaze fixation in order to measure "natural" eye movements during this task. It is known that asking subjects to imagine a visual target can change significantly eye movements elicited by neck torsion (see reference 13). After each trial, subjects were asked for comments about their sensations of movement. We also asked them to mimic the movement by manipulating a simple cut-out figure of the head and trunk to obtain an admittedly crude but objective measure of their perception. These artificial models of the subject's head and trunk (similar to those displayed in the figure, bottom) were made of cardboard and mounted on a small square tablet $(30 \times 30 \mathrm{~cm})$. The axes of head and trunk rotation were collinear. Normal subjects and patients with right brain lesions used the right hand to manipulate the model while the experimenter kept the tablet in a horizontal position in front of them. Patients with left brain lesion (and right hemiparesis) used the left hand. This subjective amplitude (expressed in degrees) of head or trunk rotation was measured by a protractor.

Horizontal eye movements were measured by means of an infrared video-nystagmographic technique (Veonysä, France) and recorded on a personal computer with a sampling rate of 50 seconds $\mathrm{s}^{-1}$. The resolution and bandwidth of the video-based eye movement recording system were $0.08^{\circ}$ and 0 to $25 \mathrm{~Hz}$, respectively. Deviation from linearity for eye deviations of lower than $25^{\circ}$ was less than $5 \%$. The subject wore light goggles with an attached video camera recording the right eye and the left eye was blindfolded. Calibration of eye movements was performed before each trial in the following way. First, the left blindfold was removed. Then the subject had to fixate alternately two red light spots $(8 \mathrm{~mm}$, at a distance of $1.5 \mathrm{~m}) 20^{\circ}$ to the left and to the right respectively. The video camera recorded the position of the right eye. A special caution was undertaken for eye response calibration in RBD patients as three of them had difficulties with fixating the target in the left hemispace. In this case, calibration was performed in the visual field localized to the right of the body's sagittal midplane ( 0 and $20^{\circ}$ to the right). The light helmet for manual head fixation was mechanically independent of goggles with the attached video camera and, thus, the pressure applied to the subject's head (to immobilize it)

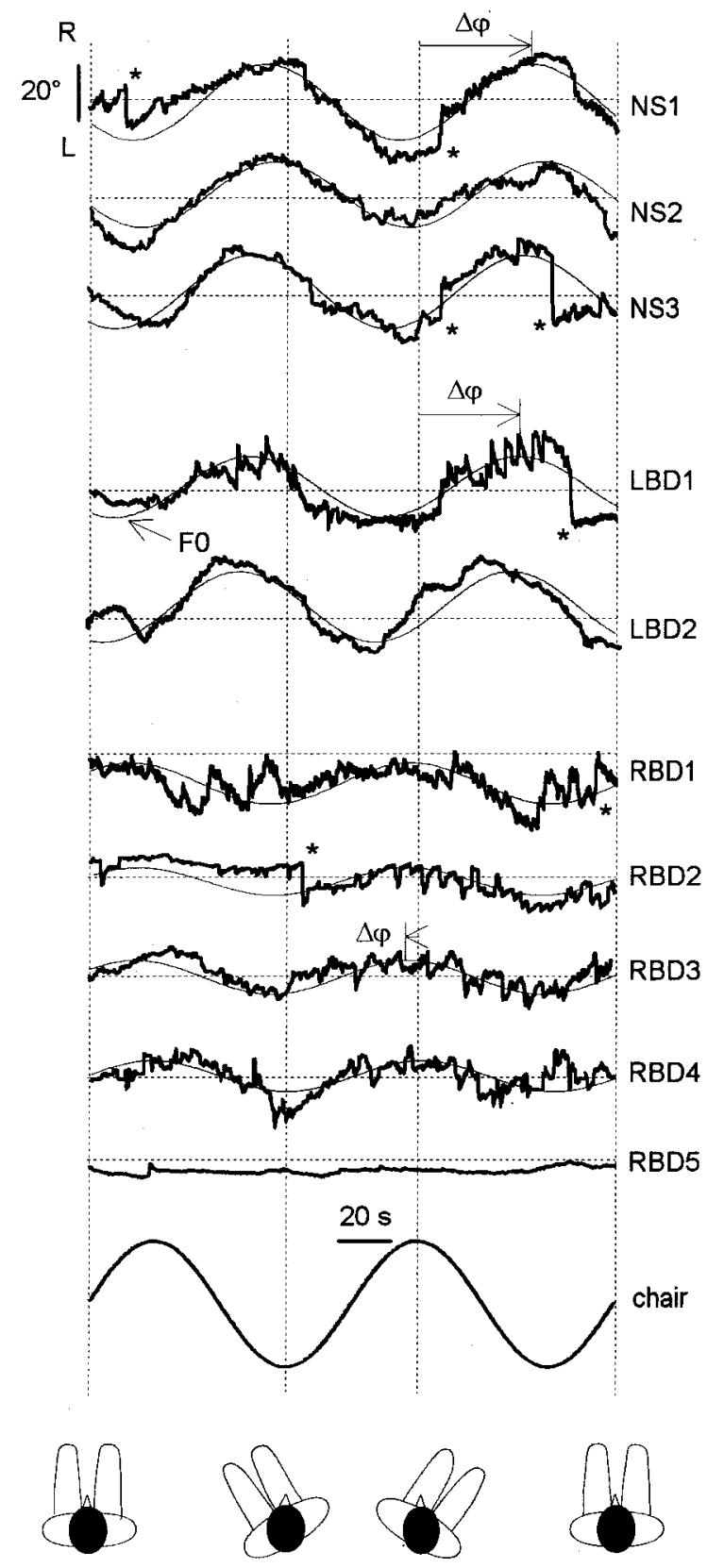

Figure. Eye movements in three normal subjects, two subjects with left brain damage (LBD), and five patients with right brain damage (RBD). Schematic drawings of trunkon-head rotations are also shown to ease inspection. Horizontal dotted lines represent neutral eye positions (head sagittal plane), thin sinusoidal lines represent fundamental harmonics (FO) of eye movements, and $\Delta \varphi$ the phase of the FO (time shift of the FO relative to the chair movement). Asterisks mark large saccades.

could not cause significant displacements of the eye movement system with respect to the subject's head. We verified a possible contribution of goggle displacements during slow trunk rotations in two normal subjects, asking them to fixate a visual target (at a distance of $1.5 \mathrm{~m}$ ) with the left eye while recording the movement of the right eye. Eye deviations were rather small (the fundamental harmonic of eye movements did not exceed $2^{\circ}$ ). 
Data analysis. Before analyzing eye movements, all artifacts due to blinking were deleted manually and the gaps were filled by straight lines. Fourier analysis was used to calculate the amplitude and phase shift of the fundamental frequency of the eye movement signal relative to the chair sinusoidal movement. The gain was defined as the ratio of this amplitude to the amplitude of chair movement. The percent variance of the original signal $(X \mathrm{i})$ accounted for by the fundamental harmonic (FOi) was taken as a measure of goodness of fit:

$$
\frac{\sum_{i=1}^{k n}\left(X_{\mathrm{i}}-F 0_{\mathrm{i}}\right)^{2}}{\sqrt{\sum_{i=1}^{k n}\left(X_{\mathrm{i}}\right)^{2} \cdot \sum_{i=1}^{k n}\left(F 0_{\mathrm{i}}\right)^{2}}} \cdot 100
$$

where $\mathrm{n}$ is the number of points in 1 cycle and $\mathrm{k}$ is the number of cycles included in the analysis $(\mathrm{n}=50 \mathrm{~Hz} \cdot 100$ $\mathrm{s}, \mathrm{k}=2$ ). Also, the mean eye-in-orbit position was calculated for each subject over the two cycles of chair movement to assess whether eye movements during cervical stimulation in darkness were deviated toward the ipsilesional side in patients.

Results. All normal subjects perceived an "illusory" head rotation in space during slow chair movements (as if the trunk was stationary relative to the room). Interestingly, subjects overestimated the actual amplitude $\left(30^{\circ}\right)$ of head rotations relative to the chair (head-on-trunk rotations): they indicated the angle $57 \pm 19^{\circ}$ (from $30^{\circ}$ up to $90^{\circ}$ ). The figure allows a comparison of typical eye movements obtained from three normal subjects (NS1, NS2, NS3) and patients. On the record of subject NS1, the eye showed a small amplitude (less than $3^{\circ}$ ) horizontal nystagmus for which the slow phase (less than $0.7^{\circ}$ second) depended on the direction of movement. This nystagmus is less apparent in other subjects. In addition to the nystagmus, large saccades could be seen (asterisks in the figure). However, the most striking component of the eye movement trace in normal subjects was a large horizontal deviation with a quasi-sinusoidal waveform. It was obvious that all normal subjects tended to slowly shift their eyes in the direction opposite to that of chair rotations; that is, in the direction of illusory head rotations (see the figure).

The percent variance of the eye movements accounted for by the fundamental harmonic was $77 \pm 13 \%$. Therefore, horizontal eye deviations had a reasonable sinusoidal shape, allowing us to apply Fourier analysis and to use the fundamental frequency for estimation of the gain and phase of eye movements. The phase of the fundamental harmonic (F0) was not exactly $180^{\circ}$ and ranged between 118 and $164^{\circ}$ (mean $139 \pm 16^{\circ}$ ). Thus, there was a slight anticipation of eye deviations relative to the actual headon-trunk rotations. The gain of the F0 ranged between 0.25 and 0.85 (mean $0.49 \pm 0.18$ ). The mean eye-in-orbit position (with respect to the head sagittal plane) for normal subjects during two cycles of slow chair rotations in darkness was $1 \pm 8^{\circ}$.

LBD patients displayed perceptual responses and eye movements similar to those of normal subjects (see the figure). Both verbally and using the artificial model of head and trunk they indicated a percept of head rotation in space $\left(30\right.$ to $\left.60^{\circ}\right)$. The percent variance of the eye move- ments accounted for by the fundamental harmonic was $70 \pm 4 \%$. The gains of the F0 for the two LBD patients were 0.51 and 0.32 , and the phases were $107^{\circ}$ and $117^{\circ}$. For LBD patients, the mean eye-in-orbit position during two cycles of slow chair rotations in darkness was $-1 \pm 3^{\circ}$.

In contrast to normal subjects, RBD patients demonstrated either eye movements in the direction of trunk rotation (opposite to the normal response) or no significant eye deviations altogether (see the figure): the gain of the F0 ranged between 0.08 and 0.78 but the phase $\left(-9 \pm 21^{\circ}\right)$ was opposite to that of the normal subjects. Percent of total variance of eye movements explained by the fundamental harmonic was relatively small for RBD patients $(49 \pm 14 \%)$. It is worth also noting that, on average, neckinduced eye movements were symmetrically distributed to the "left" and "right" and thus the mean eye-in-orbit position ( $-2 \pm 7^{\circ}$ across the five patients) was not biased toward the ipsilesional side.

RBD patients reported rather inconsistent perceptual responses, which are summarized in table 2. Two of them (Patients 1 and 5) reported alternating head rotations in space; however, their perception was sometimes asymmetrical and the subjective amplitude was smaller than that of the normal subjects. Another patient reported (and showed it by manipulating the cut-out figure of the head and trunk) paradoxical head rotation only to the left (see table 2, Patient 3, trial 1). Strikingly, two patients reported no motion at all (Patient 2 and 4).

Discussion. The results demonstrated that passive head-fixed cervical rotation in darkness produced distinct effects on oculomotor responses in normal subjects and patients with unilateral cerebral lesions. Eye movements in the direction of illusory head rotations were typical for normal subjects and for LBD patients. On the contrary, RBD patients did not display such a behavior: they showed either opposite eye movements or no eye deviations altogether (see the figure). Furthermore, RBD patients displayed difficulties in constructing a stable internal representation of changes in body-in-space configuration that occurred during cervical stimulation in darkness (see table 2). In contrast, normal subjects and LBD patients clearly reported an illusory head rotation in space.

Sensory signals related to passive externally induced head movements are different from those induced by active self-generated voluntary head rotations as they are not accompanied by corollary discharge. Nevertheless, cervico-ocular responses in darkness might reflect the inherent mechanisms of the gaze control system. In normal subjects, orienting eye movements in the direction opposite to trunk rotation (see the figure) likely reflect natural eye-head coordination mechanisms. These movements can be considered as anticipatory in the sense that they constantly anticipate future gaze direction during cervical stimulation. Neurophysiologic studies in primates confirm the existence of cortical networks for synergetic eyehead-trunk behavior. For instance, the direction of saccades evoked by electrical microstimulation from intercalated zone of posterior parietal cortex is sig- 
Table 2 Sensations of rotation (1 and 2 denote two successive trials) in normal subjects and in patients with unilateral cerebral lesions

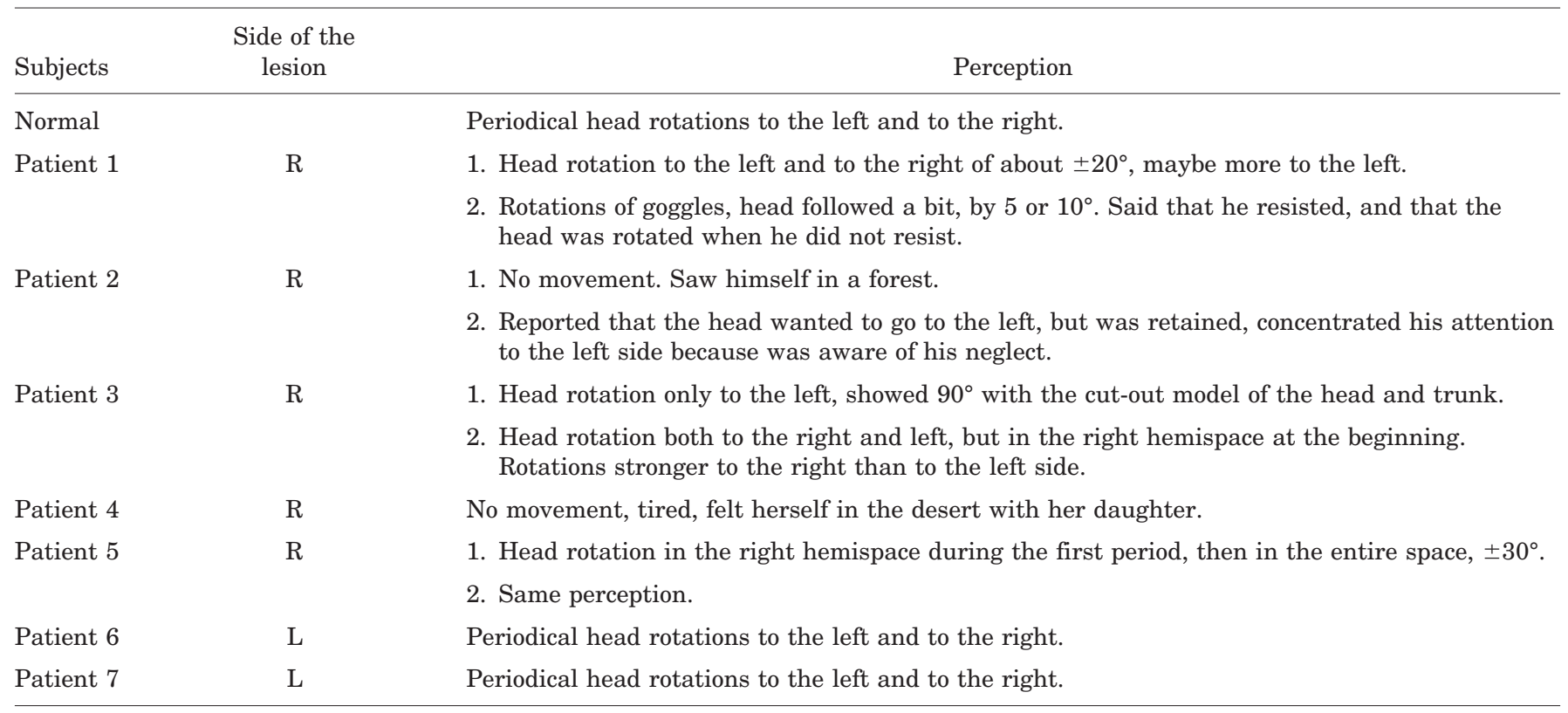

nificantly influenced by static head-on-trunk position: shifting the head to the right displayed the goal zone to the right, and, conversely, shifting the head to the left moved the goal zone to the left. ${ }^{21} \mathrm{RBD}$ patients failed to show eye deviations in the direction opposite to trunk rotation, in addition to their perceptual difficulties. The lack of a stable internal representation of head motion in RBD patients might directly account for the lack of reorienting eye movements. Alternatively, the impairment of some common neural pathways could affect both perceptual responses and eye movements. Two RBD patients (Patients 1 and 5, table 2) perceived alternating head rotations in space (Patient 5 did not show anymore clinical signs of neglect; table 1) although they did not display "anticompensatory" eye movements in the direction of head relative to trunk rotations. Therefore, the absence of anticompensatory eye movements during cervical stimulation in darkness might reflect the lack of orienting responses in RBD patients.

Anticipatory space-oriented ocular reactions ${ }^{14,15,22,23}$ belong to phylogenetically old neural mechanisms and are probably related to directed attention within extrapersonal space. It has been suggested that, in human brain, a functional asymmetry for attentional/intentional systems exists such that the right cerebral hemisphere may direct the eyes toward either hemispace, whereas the left cerebral hemisphere is limited in its capacity to direct the eyes ipsilaterally. ${ }^{24,25}$ This functional cerebral asymmetry for gaze may be due to an evolutionary loss of attentional mechanisms by the left cerebral hemisphere as language function developed. ${ }^{24}$ In addition to a functional specialization for the distribution of directed attention within extrapersonal space, the right cerebral hemisphere of dextrals may act as a distributed sen- sorimotor interface for anticipatory coordinating gaze behavior.

\section{Acknowledgment}

The authors thank Monique Rohr for her help with the experiments.

\section{References}

1. Grüsser OJ, Landis T. Visual agnosia and other disturbances of visual perception and cognition, vol. 12. London: MacMillan, 1991.

2. Cubelli R, Pugliese M, Gabellini AS. The effect of space location on neglect depends on the nature of the task. J Neurol 1994;241:611-614.

3. Doricchi F, Guariglia C, Paolucci S, Pizzamiglio L. Asymmetry of rapid eye movements in chronic unilateral neglect does not change with behavioral improvement induced by rehabilitation treatment. Electroencephalogr Clin Neurophysiol 1996; 98:51-58.

4. Vuilleumier P, Valenza N, Mayer E, Reverdin A, Landis T. Near and far visual space in unilateral neglect. Ann Neurol 1998;43:406-410.

5. Rubens AB. Caloric stimulation and unilateral visual neglect. Neurology 1985;35:1019-1024.

6. Vallar G, Guariglia C, Magnotti L, Pizzamiglio L. Optokinetic stimulation affects both vertical and horizontal deficits of position sense in unilateral neglect. Cortex 1995;31:669-683.

7. Pizzamiglio L, Vallar G, Doricchi F. Gravity and hemineglect. NeuroReport 1995;7:370-371.

8. Karnath HO, Fetter M, Dichgans J. Ocular exploration of space as a function of neck proprioceptive and vestibular input-observations in normal subjects and patients with spatial neglect after parietal lesions. Exp Brain Res 1996;109: 333-342.

9. Andersen RA, Snyder LH, Bradley DC, Xing J. Multimodal representation of space in the posterior parietal cortex and its use in planning movements. Annu Rev Neurosci 1997;20:303330.

10. Penfield W. Vestibular sensation and the cerebral cortex. Ann Otology 1957;66:691-698.

11. Vuilleumier P, Valenza N, Mayer E, Perrig S, Landis T. To see better to the left when looking more to the right: effects of gaze direction and frames of spatial coordinates in unilateral neglect. J Int Neuropsychol Soc 1999;5:75-82. 
12. Schindler I, Kerkhoff G. Head and trunk orientation modulate visual neglect. NeuroReport 1997;8:2681-2685.

13. Ivanenko YP, Viaud-Delmon I, Sémont A, Gurfinkel VS, Berthoz A. Eye movements during torso rotations in labyrinthine-defective subjects. J Vestib Res 1999;9:401-412.

14. Grasso R, Prévost P, Ivanenko YP, Berthoz A. Eye-head coordination for the steering of locomotion in humans: an anticipatory synergy. Neurosci Lett 1998;253:115-118.

15. Siegler I, Israel I, Berthoz A. Shift of the beating field of vestibular nystagmus: an orientation strategy? Neurosci Lett 1998;254:93-96.

16. Viaud-Delmon I, Siegler I, Israel I, Jouvent R, Berthoz A. Eye deviation during rotation in darkness in trait anxiety: an early expression of perceptual avoidance? Biol Psychiatry 2000;47:112-118.

17. Gurfinkel VS, Levik YS. The suppression of cervico-ocular response by the haptokinetic information about the contact with a rigid, immobile object. Exp Brain Res 1993;95:359364.

18. Mergner T, Huber W, Becker W. Vestibular-neck interaction and transformation of sensory coordinates. J Vest Res 1997;7: 347-367.

19. Wilson B, Cockburn J, Halligan P. Behavioural inattention test. Titchfield: Thames Valley Test Co., National Rehabilitation Services, 1987.

20. Guariglia C, Antonucci G. Personal and extrapersonal space: a case of neglect dissociation. Neuropsychologia 1992;30:10011009.

21. Thier P, Andersen RA. Electrical microstimulation distinguishes distinct saccade-related areas in the posterior parietal cortex. J Neurophysiol 1998;80:1713-1735.

22. Chun KS, Robinson DA. A model of quick phase generation in the vestibuloocular reflex. Biol Cybern 1978;28:209-221.

23. Land MF, Lee DN. Where we look when we steer. Nature 1994;369:742-744.

24. Mesulam MM. From sensation to cognition. Brain 1998; 121(part 6):1013-1052.

25. Meador KJ, Loring DW, Lee GP, et al. Hemisphere asymmetry for eye gaze mechanisms. Brain 1989;112(part 1):103-111.

\title{
IgG receptor IIa alleles determine susceptibility and severity of Guillain-Barré syndrome
}

\author{
W.-L. van der Pol, MD; L.H. van den Berg, MD; R.H.M. Scheepers, MSc; J.G. van der Bom, MD; \\ P.A. van Doorn, MD; R. van Koningsveld, MD; M.C.L. van den Broek, MD; J.H.J. Wokke, MD; \\ and J.G.J. van de Winkel, $\mathrm{PhD}$
}

\begin{abstract}
Article abstract-Objective: Guillain-Barré syndrome (GBS) is characterized by nerve infiltration of leukocytes and autoantibodies of the immunoglobulin G (IgG) isotype directed against nerve constituents. Leukocyte receptors for IgG $(\mathrm{F} c \gamma \mathrm{R})$ constitute an important link between the humoral and cellular parts of the immune system and confer potent cellular effector functions to myelin-directed antibodies. Three $\mathrm{F} c \gamma \mathrm{R}$ subclasses exhibit genetically determined biallelic functional polymorphisms (FcyRIIa: R131 versus H131; Fc $\gamma$ RIIIa: 158V versus 158F; Fc $\gamma R I I I b:$ NA1 versus NA2) that determine efficacy of the cellular immune response. To study the relevance of these polymorphisms for susceptibility and severity of GBS, we compared Fc $\gamma$ R genotype distributions in GBS patients with those in controls. Methods: Genomic DNA was isolated from whole blood of 31 randomly selected patients with GBS and 187 healthy blood donors. Genotypes of the three polymorphic Fc $\gamma$ R genes were determined by PCR. Results: Fc $\gamma$ RIIa-H131 homozygosity was significantly increased in patients as compared with healthy controls (OR 2.45; 95\% CI 1.12 to $5.36 ; p=0.037$ ). Furthermore, FcyRIIa-H131 homozygous GBS patients had a higher risk for severe disease than did patients with other genotypes (OR 18.57; 95\% CI 1.95 to 176.49; $p=0.007)$. Conclusion: Fc $\gamma$ RIIa allotypes capable of initiating efficient cellular effector functions are associated with increased risk for GBS and a more severe disease course. Fc $\gamma R$ alleles may constitute novel genetic risk markers for GBS. Key words: Guillain-Barré syndrome-FcyR alleles-Polymorphism.
\end{abstract}

NEUROLOGY 2000;54:1661-1665

There is evidence that humoral as well as cellular branches of the immune system are involved in the pathogenesis of Guillain-Barré syndrome (GBS). Infiltration of monocytes/macrophages $(\mathrm{M} \phi)$ has been observed in sural nerve biopsies and postmortem peripheral nervous system material. ${ }^{1-8} \mathrm{M} \phi$ are professional phagocytes with potent immune modulatory capacities, including the production and excretion of

From the Departments of Immunology (Drs. van der Pol, Scheepers, and van de Winkel) and Neurology (Drs. van den Berg, van den Broek, and Wokke), Julius Centre for Patient Oriented Research (Dr. van der Bom), University Hospital Utrecht; and Department of Neurology Dijkzigt University Hospital Rotterdam (Drs. van Doorn and van Koningsveld), the Netherlands.

Supported by grant 950-10-624 from the Netherlands Organization for Scientific Research (NWO) (W.-L.v.d.P.) and by a fellowship of the Royal Netherlands Academy of Arts and Sciences (L.H.v.d.B.).

Received August 4, 1999. Accepted in final form January 18, 2000.

Address correspondence and reprint requests to Dr. Leonard H. van den Berg, Department of Neurology, University Hospital Utrecht, Heidelberglaan 100, 3584 CX Utrecht, the Netherlands; e-mail: L.H.vandenBerg@neuro.AZU.nl 